\title{
NADPH oxidase as a therapeutic target in Alzheimer's disease Michelle L Block
}

\author{
Address: Department of Anatomy and Neurobiology, Virginia Commonwealth University Medical Campus, Richmond, VA 23298, USA \\ Email: Michelle L Block - Block@vcu.edu
}

from $8^{\text {th }}$ International Conference on Alzheimer's Disease Drug Discovery

New York, NY, USA. 15-16 October 2007

Published: 3 December 2008

BMC Neuroscience 2008, 9(Suppl 2):S8 doi:10.1 186/147|-2202-9-S2-S8

This article is available from: http://www.biomedcentral.com/I47I-2202/9/S2/S8

(c) 2008 Block; licensee BioMed Central Ltd.

This is an open access article distributed under the terms of the Creative Commons Attribution License (http://creativecommons.org/licenses/by/2.0),

which permits unrestricted use, distribution, and reproduction in any medium, provided the original work is properly cited.

\begin{abstract}
At present, available treatments for Alzheimer's disease (AD) are largely unable to halt disease progression. Microglia, the resident macrophages in the brain, are strongly implicated in the pathology and progressively degenerative nature of $A D$. Specifically, microglia are activated in response to both $\beta$ amyloid $(A \beta)$ and neuronal damage, and can become a chronic source of neurotoxic cytokines and reactive oxygen species (ROS). NADPH oxidase is a multi-subunit enzyme complex responsible for the production of both extracellular and intracellular ROS by microglia. Importantly, NADPH oxidase expression is upregulated in $A D$ and is an essential component of microglia-mediated $A \beta$ neurotoxicity. Activation of microglial NADPH oxidase causes neurotoxicity through two mechanisms: I) extracellular ROS produced by microglia are directly toxic to neurons; 2 ) intracellular ROS function as a signaling mechanism in microglia to amplify the production of several pro-inflammatory and neurotoxic cytokines (for example, tumor necrosis factor- $\alpha$, prostaglandin E2, and interleukin-I $\beta$ ). The following review describes how targeting NADPH oxidase can reduce a broad spectrum of toxic factors (for example, cytokines, ROS, and reactive nitrogen species) to result in inhibition of neuronal damage from two triggers of deleterious microglial activation ( $A \beta$ and neuron damage), offering hope in halting the progression of $A D$.
\end{abstract}

\section{Introduction}

Alzheimer's disease (AD) affects more than 4 million people in the United States [1] and an estimated 27 million are affected worldwide [2]. Increasing with the aging population, the number of affected individuals is expected to triple by 2050 [1]. AD is a devastating disease, aggressively eroding the memory and cognitive function of patients across time, while robbing families, friends, and caretakers of their loved ones. At present, available treatments are unable to halt the progression of $\mathrm{AD}$, making the identification of novel treatments for prevention and neuroprotection a pressing scientific concern. The following review centers on the role of microglia, the resident innate immune cells in the brain, and how this cell type contrib- utes to progressive neuron damage, the role of NADPH oxidase in deleterious microglial activation, and how we may be able to target this key neurotoxic process to halt neurodegenerative diseases such as $\mathrm{AD}$.

\section{Microglia and inflammation-mediated neurodegeneration}

There is a wealth of evidence demonstrating that microglia, the resident innate immune cells in the brain, can become deleterious and damage neurons $[3,4]$. This process is implicated as an underlying mechanism in diverse neurodegenerative diseases, including $\mathrm{AD}[3,4]$. While microglial function is beneficial and mandatory for normal central nervous system functioning, microglia 
become toxic to neurons when they are over-activated and unregulated [4]. Microglia are activated in response to specific stimuli to produce pro-inflammatory factors (for example, tumor necrosis factor (TNF) $\alpha$, prostaglandin E2 $\left(\mathrm{PGE}_{2}\right)$, and interferon- $\gamma$ ) and reactive oxygen species (for example, ${ }^{-} \mathrm{NO}, \mathrm{H}_{2} \mathrm{O}_{2}, \mathrm{O}_{2}{ }^{-}$, , ONOO-/ONOOH), which are toxic to neurons $[4,5]$. Microglia actively monitor the brain and can become activated to cause neuron damage in response to two categories of stimuli. First, microglia can identify pro-inflammatory triggers, such as $\beta$-amyloid $(A \beta)$, resulting in activation, the production of toxic factors, and neuron death/damage (Figure 1). Second, the microglial response to neuronal damage can also become toxic (Figure 1) [5]. Current evidence demonstrates that the microglial response to neuronal damage can be longlived, self-perpetuating, and toxic to neurons $[3,5,6]$ (Figure 1). This repeating cycle of the neurotoxic activation of microglia in response to neuron injury is commonly referred to as reactive microgliosis (Figure 1). In fact, it has been proposed that deleterious microglial activation may be propagated and potentially amplified throughout multiple neurodegenerative diseases, including $\mathrm{AD}$ [3].

\section{Alzheimer's disease, microglial activation, and oxidative stress}

Pathological diagnosis of AD is characterized by the identification of insoluble extracellular plaques containing $A \beta$ and intraneuronal neurofibrillary tangles in the cortical region of the brain. The premise of microglia over-activation in $\mathrm{AD}$ has been supported by analysis of post mortem brains from $\mathrm{AD}$ patients, where there is clear evidence of microglial activation in association with lesions of senile, amyloid plaques and neurofibrillary tangles $[7,8]$. In fact, microglial activation occurs early in $\mathrm{AD}$ development, before neuropil damage, supporting a contributing role of microglia in disease pathology [9]. Further, the microglial response to $A \beta[10,11]$ and the senile plaques $[12,13]$ includes the production of toxic factors. For example, TNF $\alpha$ [14], nitric oxide [15], and superoxide [11] are produced by microglia in response to $A \beta$. Epidemiological studies have further supported the role of inflammation in $\mathrm{AD}$, where results have shown a decreased incidence and severity of $\mathrm{AD}$ in patient populations treated with nonsteroidal anti-inflammatory drugs (NSAIDs) [16-18]. Thus, evidence supports the presence of microglial activation in $\mathrm{AD}$ and that this may contribute to the pathology of the disease [19], where $A \beta$ is hypothesized to be a key element in the pro-inflammatory mechanism.

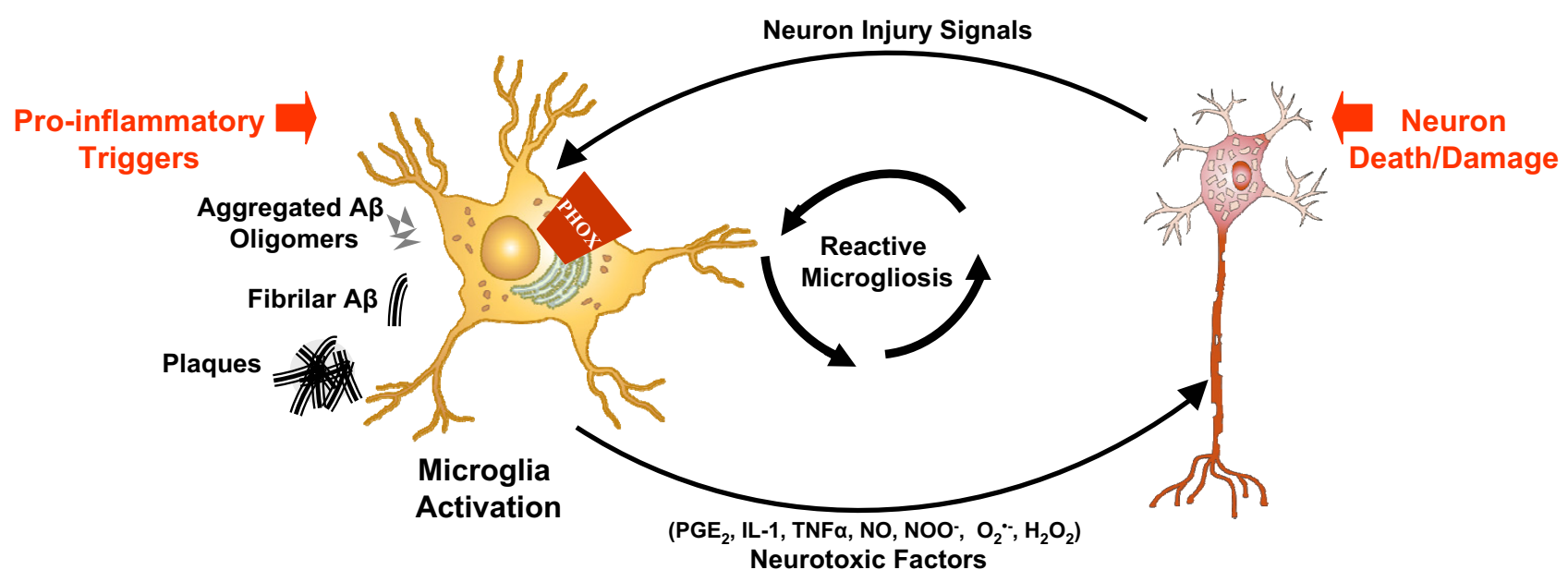

Figure I

Microglia-mediated neuron damage. Microglia activation has been implicated in the progressive nature of Alzheimer's disease. Microglia can become deleteriously activated in response to disease-specific stimuli (amyloid- $\beta$ (A $\beta$ ) oligomers, $A \beta$ fibrils, and senile plaques) to produce a catalogue of factors, such as reactive oxygen species and cytokines that are toxic to neurons. In addition to disease-specific pro-inflammatory stimuli, neuronal damage/death can also activate microglia to produce these toxic factors. This continual and self-perpetuating cycle of neuronal damage/death followed by microglial activation is commonly referred to as reactive microgliosis and may be an underlying mechanism of the progressive nature of diverse neurodegenerative diseases, including Alzheimer's disease. Although all forms of A $\beta$ have yet to be tested in detail, NADPH oxidase (also called phagocytic oxidase (PHOX)) has been implicated as a key mechanism through which microglia damage neurons in response to $A \beta$ and neuron damage/death. This figure is modified from Block et al. [3]. NO, nitric oxide; $P_{G} E_{2}$, prostaglandin E2; TNF, tumor necrosis factor. 
The amyloid hypothesis has been modified over time, but the premise has remained that $A \beta$ has a causative role in AD pathology [20], both through direct toxicity to neurons [21], and by causing neuronal damage through microglial activation [20]. $A \beta(1-40)$ and $A \beta(1-42)$ are the predominant forms of $A \beta$ in the brain, and have been implicated as active participants in the mechanism of $\mathrm{AD}$ progression. $A \beta(1-42)$ has been labeled as the more toxic of the two prevalent $A \beta$ peptides, and toxicity is dependent upon the aggregation state of $A \beta$, and the mode of toxicity (that is, directly toxic to neurons or microgliamediated neurotoxicity) $[20,22,23]$. The aggregation state of $A \beta$ required to cause microglia activation and neuron damage is disputed. For example, small, soluble oligomers of $A \beta$ have been shown to activate microglia [24], but the majority of studies suggest that the larger, insoluble $\mathrm{A} \beta$ aggregates, and fibrillized $\mathrm{A} \beta$, are the more potent stimuli $[25,26]$. Undoubtedly, $A \beta$ has been shown to both recruit and activate microglia $[8,14,27]$, suggesting a critical role in $\mathrm{AD}$ progression.

In addition to microglial activation and cytokine production, oxidative stress is closely associated with $\mathrm{AD}$ [28], where early $\mathrm{AD}$ pathology shows evidence of oxidative damage [29-31], indicating a potential role in disease pathogenesis. The detailed mechanisms of how oxidative stress causes $\mathrm{AD}$ are complex and poorly understood, but $\mathrm{AD}$-specific patterns of oxidative stress have been identified. For example, localized increases in carbonylated-, 4hydroxynonenal-, and 3-nitrotyrosine-modified proteins have been reported in hippocampus and parietal cortex of AD patient brains, demonstrating disease specific modifications due to reactive nitrogen species [32]. In fact, it has been repeatedly demonstrated that increased levels of nitrated proteins are present in AD brains [33-36], including tau nitration [37], which indicates that an increase in reactive nitrogen species affects $\mathrm{AD}$ pathology. Additionally, protein oxidation is known to induce protein aggregation, a process that has been hypothesized as a critical mechanism contributing to tau tangle formation [31], $\mathrm{A} \beta$ aggregation, and senile plaque formation [38]. Importantly, $A \beta$ is also clearly indicated as a source of oxidative stress [39], as $A \beta$ activates microglia to produce extracellular superoxide $[11,40]$. Thus, while there may be several sources and mechanisms, there is increasing support that oxidative stress contributes to $\mathrm{AD}$ pathology, and that microglia and $\mathrm{A} \beta$ may play an instigating role.

\section{NADPH oxidase, oxidative stress, and neuronal damage}

NADPH oxidase is a multi-subunit enzyme complex that is activated during host defense in phagocytes, such as microglia, to catalyze the production of superoxide from oxygen. NADPH oxidase is a member of the NOX gene family, also called NOX2 and phagocytic oxidase
(PHOX). The NADPH oxidase enzyme complex consists of the membrane bound cytochrome b558 (p22 ${ }^{\mathrm{PHOX}}$ and the enzymatic subunit, gp91 ${ }^{\text {PHOX }}$ ), several cytosolic proteins (p47 $7^{\text {PHOX }}, \mathrm{p} 67^{\text {PHOX }}$, and $\mathrm{p} 40^{\text {PHOX }}$ ), and the Rac Gprotein $[41,42]$. NADPH oxidase is activated when the cytosolic subunits are phosphorylated and Rac is activated in the cytosol, resulting in their translocation to the membrane and formation of the active NADPH oxidase complex with cytochrome b558 $[41,42]$. The end product of the enzyme is superoxide.

Recently, NADPH oxidase has been associated with neurodegenerative disorders and related complications. For example, NADPH oxidase is activated in brains from AD patients [43] and is upregulated in Parkinson's disease [44]. Interestingly, reactive oxygen species (ROS) from $\mathrm{NADPH}$ oxidase have also been shown to mediate $A \beta$ induced cerebrovascular dysfunction [45]. It is not surprising that several stimuli activate NADPH oxidase in microglia to cause neuron damage, including $A \beta[11,46]$, amyloid precursor protein [47], rotenone [48], air pollution [49], paraquat [50], substance P [51], and $\alpha$-synuclein [52]. Further, NADPH oxidase has been shown to play a role in how reactive microgliosis (the microglial response to neuron damage) causes additional neuron damage [53]. Thus, evidence supports that NADPH oxidase may be a common pathway of microglia-mediated neuronal damage.

The NOX family of proteins is expressed on diverse cell types and NADPH oxidase is present in microglia, neurons, and astrocytes. However, NADPH oxidase is present in lower amounts in cells that are not from the myeloid lineage (for example, neurons and astrocytes). Additionally, astrocytes and neurons do not express several receptors that recognize and respond to stimuli that activate NADPH oxidase in microglia, including MAC1 and subsets of scavenger receptors. Further, while NADPH oxidase can be activated in these alternative cell types, the resulting production of ROS is significantly lower than that of microglia and other cells specialized for innate immunity. Notably, a study using lipopolysaccharide (LPS) as a stimulus of microglial activation showed that only NADPH oxidase from microglia, and not astrocytes and neurons, caused the NADPH oxidase-mediated neuron damage [54]. Microglia derived from NADPH oxidase knockout mice failed to produce extracellular superoxide, expressed reduced pro-inflammatory profiles, and showed significantly less intracellular ROS [54]. Thus, microglia are the predominant source of NADPH oxidase-derived ROS and targeting microglial NADPH oxidase may be an ideal approach to attenuate deleterious activation [55].

In addition to damaging neurons through the production of extracellular superoxide, NADPH oxidase also impacts 
neuron survival by regulating the microglial pro-inflammatory response [56]. The PHOX-ROS pathway refers to the signaling mechanism resulting from the increase in intracellular ROS in phagocytes as a response to NADPH oxidase activation. The increase in intracellular ROS in phagocytes, such as microglia, includes the production of several radicals, including the superoxide anion, hydroxyl radical, lipid hydroperoxides, and their by-products (for example, $\mathrm{H}_{2} \mathrm{O}_{2}$ ) [57]. Normal cellular function and metabolism results in the production of intracellular ROS from multiple cellular sources, including mitochondrial electron transport, xanthine oxidase, peroxisomes, and the endoplasmic reticulum [57]. However, NADPH oxidase contributes to a large proportion of intracellular ROS in phagocytes in response to an immunological stimulus, where approximately $50 \%$ of the LPS-induced intracellular ROS increase in microglia is due to NADPH oxidase [54]. The relative contribution of NADPH oxidase to the increase in microglial intracellular ROS is stimulus dependent, as substance P-induced intracellular ROS is largely dependent upon NADPH oxidase [51].

NADPH oxidase enhances pro-inflammatory gene expression through several downstream signaling molecules, for example, protein kinase $\mathrm{C}$, mitogen-activated protein

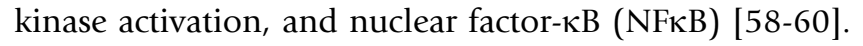
Thus, NADPH oxidase initiates an intracellular ROS signaling pathway [61] that can activate microglia and amplify the production of multiple pro-inflammatory cytokines, such as TNF $\alpha$ [54] or $\mathrm{PGE}_{2}$ [62]. In fact, several triggers of $\mathrm{NADPH}$ oxidase activation in microglia amplify proinflammatory signaling. For example, gangliosides are shown to activate microglia, where the production of interleukin (IL)-1 $\beta$, TNF- $\alpha$, and inducible nitric oxide synthase (iNOS) are attenuated by the addition of the NADPH oxidase inhibitor diphenyleneiodonium (DPI) [63]. Furthermore, both DPI and catalase (an enzyme that catalyzes the decomposition of $\mathrm{H}_{2} \mathrm{O}_{2}$ to water and oxygen) were shown to suppress LPS-induced expression of cytokines (IL-1, IL-6, and TNF $\alpha$ ), iNOS, mitogen-activated protein kinases, and NFkB phosphorylation [64]. In addition to cytokine production, NADPH oxidase has also been shown to mediate the morphological changes associated with microglial activation [54]. Thus, intracellular ROS play an essential role in the regulation of general microglial activation.

Additionally, NADPH oxidase is reported to prime microglia for enhanced sensitivity to additional stimuli. For example, rotenone [65] and neuronal death [66] have been shown to prime microglia through NADPH oxidase to synergistically enhance cytokine production and neurotoxicity upon additional exposure to LPS. Thus, not only does activation of NADPH oxidase amplify the microglial pro-inflammatory response, it also changes this response to additional stimuli, allowing a robust pro-inflammatory response to previously innocuous stimuli. Taken together, microglial NADPH oxidase activation, and the production of ROS, have been implicated as critical regulators of microglia-mediated neurotoxicity and represent ideal therapeutic targets.

\section{Anti-inflammatory therapy and Alzheimer's disease}

Given the strong evidence for the presence of microglial activation, oxidative stress, and pro-inflammatory factors in $\mathrm{AD}$ [67], there has been a keen interest in the potential therapeutic utility of anti-inflammatory drugs $[68,69]$. Unfortunately, while many epidemiological and animal studies have supported the use of this approach, clinical trials have not been successful.

The bulk of previous anti-inflammatory studies have focused predominantly on NSAIDs [70]. Epidemiological studies have shown that patients taking anti-inflammatory medicine for rheumatoid arthritis were six times less likely to develop AD [71]. Other epidemiological studies have also shown that diets high in anti-oxidants may decrease the risk of developing $\mathrm{AD}$ [72]. Additionally, a separate epidemiological study shows that taking NSAIDs for at least one month is associated with lower probability of AD [73]. Interestingly, NSAIDs may also protect against cognitive decline in the elderly without $\mathrm{AD}$ diagnosis [74]. However, only two pilot trials have shown some promise $[73,75]$, and the majority of clinical results for NSAIDS have been disappointing. One explanation proposed for the success of NSAIDs in both animal and epidemiological studies, yet failure in clinical trails, is that NSAIDs may be able to prevent disease, rather than treat symptoms [73]. Another hypothesis is that the anti-inflammatory compounds tested may not be focusing on the most deleterious and damaging consequences of microglial activation.

\section{Neuroprotection and NADPH oxidase inhibitors} Traditional NSAIDs, such as indomethacin and aspirin, target a single pro-inflammatory factor, such as $\mathrm{PGE}_{2}$, where the target is the downstream result of the toxic microglial pro-inflammatory response. However, microglia produce several pro-inflammatory factors and ROS [4], where successful inhibition of microglia-mediated toxicity will likely require the attenuation of a broad spectrum of factors. To address this problem, our approach has been to focus on regulating the microglial function upstream, before the response becomes toxic, and to focus on what we believe to be the most detrimental component of microglial activation, NADPH oxidase activation (Figure 2). 
Recently, several peptides (pituitary adenylate cyclaseactivating polypeptide, dynorphin, glycine-glycine-phenylalanine, leucine enkephalin, and des-tyrosine leucine enkephalin) [76-78], antibiotics (minocycline) [79], and small molecules (dextromethorphin, statins, naloxone, and sinolimine) $[77,80,81]$ have been identified that inhibit NADPH oxidase and are neuroprotective (Figure 2 ). For example, dextromethorphan (DXM) illustrates the broad therapeutic utility of NADPH oxidase inhibitors [82]. DXM is a noncompetitive $\mathrm{N}$-methyl-d-aspartate (NMDA) receptor antagonist that is widely and commercially used as an antitussive agent, and is neuroprotective through inhibition of microglial activation and NADPH oxidase activation [83,84]. In addition, DXM has been tested for a variety of conditions, and has shown activity in ameliorating pain [85] and as a neuroprotectant against focal ischemia [86]. In particular, DXM is noted to have anti-inflammatory effects [87], and is reported to protect against neuron damage through the inhibition of micro- glial activation in methamphetamine-induced neurotoxicity [88], and in studies of in vitro [83,89] and in vivo [90] models of Parkinson's disease. While the NMDA inhibitor dizocilpine maleate fails to inhibit NADPH oxidase, and is not neuroprotective [84], a recent report showed that the NMDA receptor antagonist memantine may also be neuroprotective through microglia inhibition [91]. While it is clear that DXM works through the inhibition of NADPH oxidase $[83,84]$, and inhibition of the NMDA receptor does not always result in neuroprotection [89], the role of the NMDA receptor in DXM inhibition of NADPH oxidase remains unclear. Notably, DXM, statins, and naloxone have a history of safe therapeutic use, supporting that inhibition of NADPH oxidase is safe. For the purpose of targeting this enzyme complex for the therapeutic treatment of neurodegenerative diseases, future efforts will need to focus on the identification of both the detailed mechanisms of NADPH oxidase inhibition and developing more specific inhibitors.

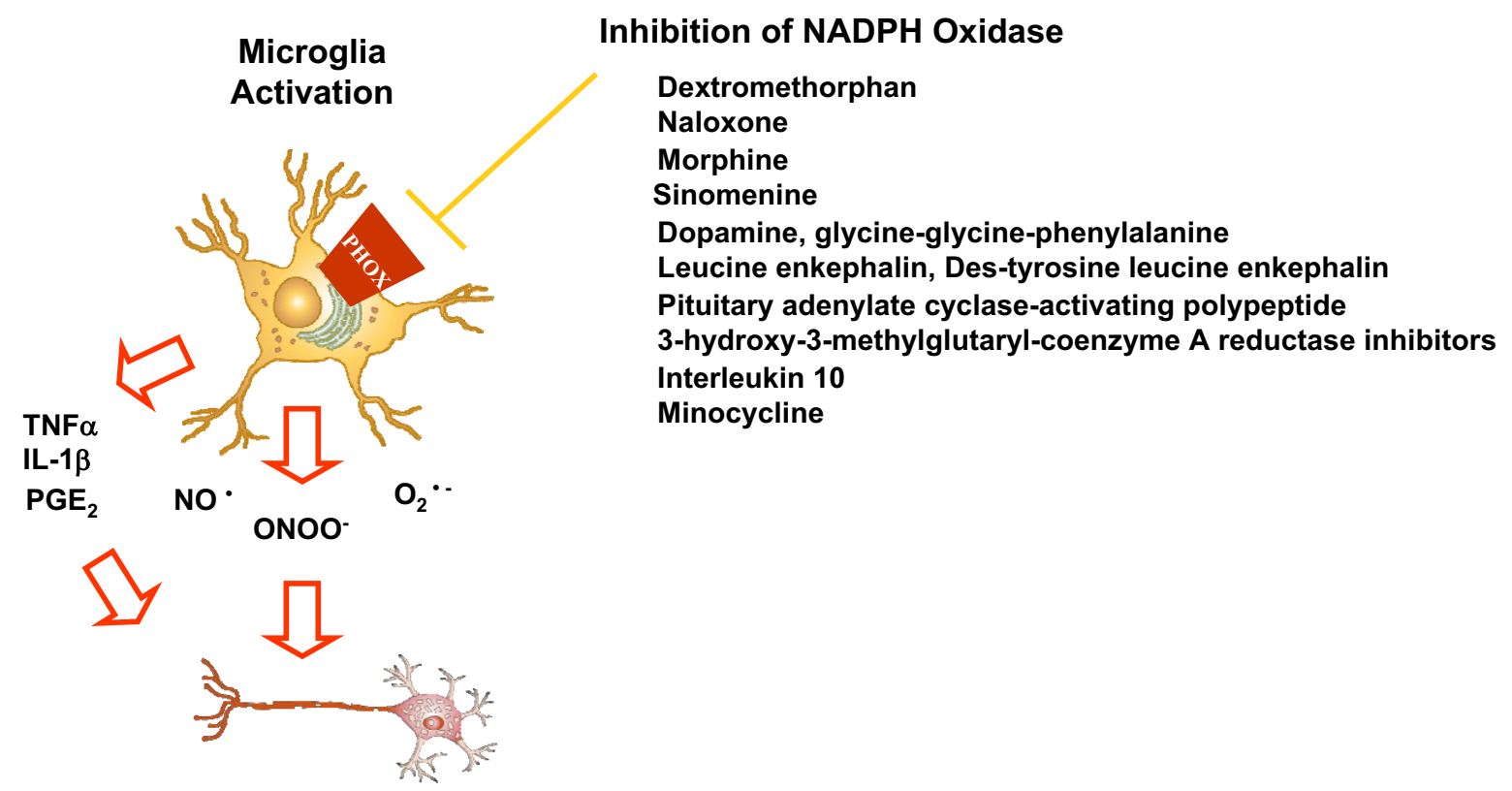

Neuron Death/Damage

\section{Figure 2}

NADPH oxidase inhibition targets deleterious microglial activation. Increasing evidence points to NADPH oxidase (also called phagocytic oxidase (PHOX)) as a critical mechanism of microglia-mediated neuron damage. Traditional anti-inflammatory approaches focus on specific downstream targets, such as prostaglandin E2 (PGE 2 ). However, targeting NADPH oxidase inhibits the global pro-inflammatory response further upstream in the process of neurotoxic microglial activation and is able to inhibit a broad spectrum of cytokines, nitric oxide, and reactive oxygen species to confer neuroprotection. At present, small molecules, peptides, anti-inflammatory cytokines, and an antibiotic have been identified that inhibit microglial NADPH oxidase and are neuroprotective. Further research is warranted to discover the mechanisms through which these seemingly diverse compounds work and to identify more specific inhibitors of this key neurotoxic pathway. This figure is modified from Zhang et al. [82]. IL, interleukin; TNF, tumor necrosis factor. 


\section{Conclusion}

Increasing evidence points to NADPH oxidase as a critical component of deleterious microglial activation. Key components of $\mathrm{AD}$ pathology, for example, $\mathrm{A} \beta$ fibrils and plaques, can serve as triggers of microglial NADPH oxidase activation and associated neuron damage. Additionally, NADPH oxidase has been implicated in the neurotoxic response of microglia to neuronal damage. Activation of microglial NADPH oxidase causes neuron damage through the production of neurotoxic extracellular ROS, enhancement of the global microglial proinflammatory response, and the priming of microglia to have a heightened sensitivity to previously innocuous stimuli. In this manner, inhibiting NADPH oxidase may target the progressive cycle of deleterious microglial activation that fuels progressive neurotoxicity. At present, while 'old drugs' have been identified that are neuroprotective through their effects on NADPH oxidase, and may be useful for current therapy, future research must focus on elucidating the detailed molecular mechanisms of the diverse list of NADPH oxidase inhibitors and then move forward with developing more specific, potent, and safe agents.

\section{List of abbreviations used}

$\mathrm{A} \beta$ : beta amyloid; AD: Alzheimer's disease; DPI: diphenyleneiodonium; DXM: dextromethorphan; IL: interleukin; iNOS: inducible nitric oxide synthase; NMDA: Nmethyl-d-aspartate; NSAID: nonsteroidal anti-inflammatory drug; $\mathrm{PGE}_{2}$ : prostaglandin E2; PHOX: phagocytic oxidase; ROS: reactive oxygen species; TNF: tumor necrosis factor.

\section{Competing interests}

The author declares that they have no competing interests.

\section{Acknowledgements}

This work was supported by the NIH Pathway to Independence Award (NIEHS IK99ESOI549-0I) and the ADDF/ISOA.

This article has been published as part of BMC Neuroscience Volume 9 Supplement 2: 2008 Proceedings of the $8^{\text {th }}$ International Conference on Alzheimer's Disease Drug Discovery The full contents of the supplement are available online at http://www.biomedcentral.com/I47I-2202/9?issue=S2.

\section{References}

I. Hebert LE, Scherr PA, Bienias JL, Bennett DA, Evans DA: Alzheimer disease in the US population: prevalence estimates using the 2000 census. Arch Neurol 2003, 60:1119-1 122.

2. Wimo A, Jonsson L, Winblad B: An estimate of the worldwide prevalence and direct costs of dementia in 2003. Dement Geriatr Cogn Disord 2006, 21 : I75-181.

3. Block ML, Zecca L, Hong JS: Microglia-mediated neurotoxicity: uncovering the molecular mechanisms. Nat Rev Neurosci 2007, 8:57-69.

4. Block ML, Hong JS: Microglia and inflammation-mediated neurodegeneration: multiple triggers with a common mechanism. Prog Neurobiol 2005, 76:77-98.
5. Block ML, Hong JS: Chronic microglial activation and progressive dopaminergic neurotoxicity. Biochem Soc Trans 2007, 35: I I 27-I I 32.

6. McGeer PL, Schwab C, Parent A, Doudet D: Presence of reactive microglia in monkey substantia nigra years after I-methyl-4phenyl-I ,2,3,6-tetrahydropyridine administration. Ann Neurol 2003, 54:599-604.

7. McGeer PL, Itagaki S, Tago H, McGeer EG: Reactive microglia in patients with senile dementia of the Alzheimer type are positive for the histocompatibility glycoprotein HLA-DR. Neurosci Lett 1987, 79:195-200.

8. Sasaki A, Yamaguchi H, Ogawa A, Sugihara S, Nakazato Y: Microglial activation in early stages of amyloid beta protein deposition. Acta Neuropathol 1997, 94:316-322.

9. Cagnin A, Brooks DJ, Kennedy AM, Gunn RN, Myers R, Turkheimer $\mathrm{FE}$, Jones T, Banati RB: In-vivo measurement of activated microglia in dementia. Lancet 2001, 358:46 I-467.

10. Combs CK, Johnson DE, Karlo JC, Cannady SB, Landreth GE: Inflammatory mechanisms in Alzheimer's disease: inhibition of beta-amyloid-stimulated proinflammatory responses and neurotoxicity by PPARgamma agonists. J Neurosci 2000, 20:558-567.

II. Qin L, Liu Y, Cooper C, Liu B, Wilson B, Hong JS: Microglia enhance beta-amyloid peptide-induced toxicity in cortical and mesencephalic neurons by producing reactive oxygen species. J Neurochem 2002, 83:973-983.

12. Van Everbroeck B, Dobbeleir I, De Waele M, De Leenheir E, Lubke U, Martin J], Cras P: Extracellular protein deposition correlates with glial activation and oxidative stress in Creutzfeldt-Jakob and Alzheimer's disease. Acta Neuropathol 2004, I 08: I 94-200.

13. Veerhuis R, Janssen I, De Groot CJ, Van Muiswinkel FL, Hack CE, Eikelenboom P: Cytokines associated with amyloid plaques in Alzheimer's disease brain stimulate human glial and neuronal cell cultures to secrete early complement proteins, but not CI-inhibitor. Exp Neurol 1999, I 60:289-299.

14. Meda L, Cassatella MA, Szendrei Gl, Otvos L Jr, Baron P, Villalba M, Ferrari D, Rossi F: Activation of microglial cells by beta-amyloid protein and interferon-gamma. Nature 1995, 374:647-650.

15. li M, Sunamoto M, Ohnishi K, Ichimori Y: beta-Amyloid proteindependent nitric oxide production from microglial cells and neurotoxicity. Brain Res 1996, 720:93-100.

16. Breitner JC, Zandi PP: Do nonsteroidal antiinflammatory drugs reduce the risk of Alzheimer's disease? N Engl J Med 200I, 345: I567-I568.

17. Stewart WF, Kawas C, Corrada M, Metter EJ: Risk of Alzheimer's disease and duration of NSAID use. Neurology 1997, 48:626-632.

18. Szekely CA, Thorne JE, Zandi PP, Ek M, Messias E, Breitner JC, Goodman SN: Nonsteroidal anti-inflammatory drugs for the prevention of Alzheimer's disease: a systematic review. Neuroepidemiology 2004, 23: I59-169.

19. Griffin WS, Sheng JG, Royston MC, Gentleman SM, McKenzie JE, Graham DI, Roberts GW, Mrak RE: Glial-neuronal interactions in Alzheimer's disease: the potential role of a 'cytokine cycle' in disease progression. Brain Pathol 1998, 8:65-72.

20. Eckman CB, Eckman EA: An update on the amyloid hypothesis. Neurol Clin 2007, 25:669-682. vi.

21. Giulian D, Haverkamp LJ, Yu JH, Karshin W, Tom D, Li J, Kirkpatrick J, Kuo LM, Roher AE: Specific domains of beta-amyloid from Alzheimer plaque elicit neuron killing in human microglia. J Neurosci 1996, 16:6021-6037.

22. Pike CJ, Walencewicz AJ, Glabe CG, Cotman CW: Aggregationrelated toxicity of synthetic beta-amyloid protein in hippocampal cultures. Eur J Pharmacol 1991, 207:367-368.

23. Pike CJ, Walencewicz AJ, Glabe CG, Cotman CW: In vitro aging of beta-amyloid protein causes peptide aggregation and neurotoxicity. Brain Res 1991, 563:31।-314.

24. Takata K, Kitamura Y, Umeki M, Tsuchiya D, Kakimura J, Taniguchi T, Gebicke-Haerter PJ, Shimohama S: Possible involvement of small oligomers of amyloid-beta peptides in 15-deoxy-delta 12, I4 prostaglandin J2-sensitive microglial activation. J Pharmacol Sci 2003, $91: 330-333$.

25. Hashioka S, Monji A, Ueda T, Kanba S, Nakanishi H: Amyloid-beta fibril formation is not necessarily required for microglial activation by the peptides. Neurochem Int 2005, 47:369-376. 
26. Casal C, Serratosa J, Tusell JM: Relationship between beta-AP peptide aggregation and microglial activation. Brain Res 2002, 928:76-84.

27. Davis JB, McMurray HF, Schubert D: The amyloid beta-protein of Alzheimer's disease is chemotactic for mononuclear phagocytes. Biochem Biophys Res Commun 1992, I 89:1096-II00.

28. Butterfield DA, Drake J, Pocernich C, Castegna A: Evidence of oxidative damage in Alzheimer's disease brain: central role for amyloid beta-peptide. Trends Mol Med 200I, 7:548-554.

29. Pratico D, Uryu K, Leight S, Trojanoswki JQ, Lee VM: Increased lipid peroxidation precedes amyloid plaque formation in an animal model of Alzheimer amyloidosis. J Neurosci 200I, 2I:4I83-4I87.

30. Pratico $D$, Sung S: Lipid peroxidation and oxidative imbalance: early functional events in Alzheimer's disease. J Alzheimers Dis 2004, 6: $171-175$

31. Butterfield DA, Sultana R: Redox proteomics identification of oxidatively modified brain proteins in Alzheimer's disease and mild cognitive impairment: insights into the progression of this dementing disorder. J Alzheimers Dis 2007, I 2:6 |-72.

32. Butterfield DA, Reed TT, Perluigi M, De Marco C, Coccia R, Keller JN, Markesbery WR, Sultana R: Elevated levels of 3-nitrotyrosine in brain from subjects with amnestic mild cognitive impairment: implications for the role of nitration in the progression of Alzheimer's disease. Brain Res 2007, I I 48:243-248.

33. Castegna A, Thongboonkerd V, Klein JB, Lynn B, Markesbery WR, Butterfield DA: Proteomic identification of nitrated proteins in Alzheimer's disease brain. J Neurochem 2003, 85: I394-|40 |

34. Smith MA, Richey Harris PL, Sayre LM, Beckman JS, Perry G: Widespread peroxynitrite-mediated damage in Alzheimer's disease. J Neurosci 1997, I 7:2653-2657.

35. Sultana R, Poon HF, Cai J, Pierce WM, Merchant M, Klein JB, Markesbery WR, Butterfield DA: Identification of nitrated proteins in Alzheimer's disease brain using a redox proteomics approach. Neurobiol Dis 2006, 22:76-87.

36. Hensley K, Maidt ML, Yu Z, Sang H, Markesbery WR, Floyd RA: Electrochemical analysis of protein nitrotyrosine and dityrosine in the Alzheimer brain indicates region-specific accumulation. J Neurosci 1998, I 8:8126-8I32.

37. Horiguchi T, Uryu K, Giasson BI, Ischiropoulos H, LightFoot R, Bellmann C, Richter-Landsberg C, Lee VM, Trojanowski JQ: Nitration of tau protein is linked to neurodegeneration in tauopathies. Am J Pathol 2003, 163:1021-1031.

38. Butterfield DA, Kanski J: Brain protein oxidation in age-related neurodegenerative disorders that are associated with aggregated proteins. Mech Ageing Dev 200I, I 22:945-962.

39. Varadarajan S, Yatin S, Aksenova M, Butterfield DA: Review: Alzheimer's amyloid beta-peptide-associated free radical oxidative stress and neurotoxicity. J Struct Biol 2000, I30: I84-208.

40. Bamberger ME, Harris ME, McDonald DR, Husemann J, Landreth GE: A cell surface receptor complex for fibrillar beta-amyloid mediates microglial activation. J Neurosci 2003, 23:2665-2674.

41. Babior BM: Phagocytes and oxidative stress. Am J Med 2000, 109:33-44

42. Babior BM: NADPH oxidase. Curr Opin Immunol 2004, 1 6:42-47.

43. Shimohama S, Tanino $H$, Kawakami N, Okamura N, Kodama $H$, Yamaguchi T, Hayakawa T, Nunomura A, Chiba S, Perry G, Smith MA, Fujimoto S: Activation of NADPH oxidase in Alzheimer's disease brains. Biochem Biophys Res Commun 2000, 273:5-9.

44. Wu DC, Teismann P, Tieu K, Vila M, Jackson-Lewis V, Ischiropoulos $\mathrm{H}$, Przedborski S: NADPH oxidase mediates oxidative stress in the I-methyl-4-phenyl-I,2,3,6-tetrahydropyridine model of Parkinson's disease. Proc Natl Acad Sci USA 2003, I 00:6 I 45-6I 50.

45. Park L, Anrather J, Zhou P, Frys K, Pitstick R, Younkin S, Carlson GA, ladecola C: NADPH-oxidase-derived reactive oxygen species mediate the cerebrovascular dysfunction induced by the amyloid beta peptide. I Neurosci 2005, 25: I769-I777.

46. Bianca VD, Dusi S, Bianchini E, Dal Pra I, Rossi F: beta-amyloid activates the 0-2 forming NADPH oxidase in microglia, monocytes, and neutrophils. A possible inflammatory mechanism of neuronal damage in Alzheimer's disease. J Biol Chem 1999, 274: I5493-15499.

47. Qin B, Cartier L, Dubois-Dauphin M, Li B, Serrander L, Krause KH: A key role for the microglial NADPH oxidase in APP. dependent killing of neurons. Neurobiol Aging 2006, 27:| $577-1587$
48. Gao HM, Hong JS, Zhang W, Liu B: Distinct role for microglia in rotenone-induced degeneration of dopaminergic neurons. J Neurosci 2002, 22:782-790.

49. Block ML, Wu X, Pei Z, Li G, Wang T, Qin L, Wilson B, Yang J, Hong JS, Veronesi B: Nanometer size diesel exhaust particles are selectively toxic to dopaminergic neurons: the role of microglia, phagocytosis, and NADPH oxidase. Faseb J 2004 I 8:1618-1620.

50. Wu XF, Block ML, Zhang W, Qin L, Wilson B, Zhang WQ, Veronesi $B$, Hong JS: The role of microglia in paraquat-induced dopaminergic neurotoxicity. Antioxid Redox Signal 2005, 7:654-66l.

5I. Block ML, Li G, Qin L, Wu X, Pei Z, Wang T, Wilson B, Yang J, Hong JS: Potent regulation of microglia-derived oxidative stress and dopaminergic neuron survival: substance $P$ vs. dynorphin. Faseb J 2006, 20:25I-258.

52. Zhang W, Wang T, Pei Z, Miller DS, Wu X, Block ML, Wilson B, Zhou $Y$, Hong JS, Zhang J: Aggregated alpha-synuclein activates microglia: a process leading to disease progression in Parkinson's disease. Faseb J 2005, I 9:533-542.

53. Gao HM, Liu B, Zhang W, Hong JS: Critical role of microglial NADPH oxidase-derived free radicals in the in vitro MPTP model of Parkinson's disease. Faseb / 2003, I 7:1954-1956.

54. Qin L, Liu Y, Wang T, Wei SJ, Block ML, Wilson B, Liu B, Hong JS: NADPH oxidase mediates lipopolysaccharide-induced neurotoxicity and proinflammatory gene expression in activated microglia. J Biol Chem 2004, 279:|4I5-I42I.

55. Wilkinson BL, Landreth GE: The microglial NADPH oxidase complex as a source of oxidative stress in Alzheimer's disease. J Neuroinflammation 2006, 3:30.

56. Clark RA, Valente AJ: Nuclear factor kappa B activation by NADPH oxidases. Mech Ageing Dev 2004, I 25:799-8I0.

57. Li Y, Trush MA: Diphenyleneiodonium, an NAD(P)H oxidase inhibitor, also potently inhibits mitochondrial reactive oxygen species production. Biochem Biophys Res Commun 1998, 253:295-299.

58. Konishi H, Tanaka M, Takemura $Y$, Matsuzaki H, Ono Y, Kikkawa U, Nishizuka $Y$ : Activation of protein kinase $\mathbf{C}$ by tyrosine phosphorylation in response to H2O2. Proc Natl Acad Sci USA 1997, 94: I I233-। I 237.

59. Guyton KZ, Gorospe M, Kensler TW, Holbrook NJ: Mitogen-activated protein kinase (MAPK) activation by butylated hydroxytoluene hydroperoxide: implications for cellular survival and tumor promotion. Cancer Res 1996, 56:3480-3485.

60. Schreck R, Rieber P, Baeuerle PA: Reactive oxygen intermediates as apparently widely used messengers in the activation of the NF-kappa B transcription factor and HIV-I. EMBO J 1991, 10:2247-2258.

61. Forman HJ, Torres M: Reactive oxygen species and cell signaling: respiratory burst in macrophage signaling. Am J Respir Crit Care Med 2002, 166:S4-8.

62. Wang T, Qin L, Liu B, Liu Y, Wilson B, Eling TE, Langenbach R, Taniura $S$, Hong JS: Role of reactive oxygen species in LPS-induced production of prostaglandin E2 in microglia. J Neurochem 2004, 88:939-947

63. Min KJ, Pyo HK, Yang MS, Ji KA, Jou I, Joe EH: Gangliosides activate microglia via protein kinase $C$ and NADPH oxidase. Glia 2004, 48: 197-206.

64. Pawate $S$, Shen $Q$, Fan F, Bhat NR: Redox regulation of glial inflammatory response to lipopolysaccharide and interferongamma. J Neurosci Res 2004, 77:540-55I.

65. Gao HM, Hong JS, Zhang W, Liu B: Synergistic dopaminergic neurotoxicity of the pesticide rotenone and inflammogen lipopolysaccharide: relevance to the etiology of Parkinson's disease. J Neurosci 2003, 23: I 228-I236.

66. Gao HM, Liu B, Zhang W, Hong JS: Synergistic dopaminergic neurotoxicity of MPTP and inflammogen lipopolysaccharide: relevance to the etiology of Parkinson's disease. Faseb J 2003, I 7:1957-1959.

67. Akiyama H, Barger S, Barnum S, Bradt B, Bauer J, Cole GM, Cooper NR, Eikelenboom P, Emmerling M, Fiebich BL, Finch CE, Frautschy S, Griffin WS, Hampel H, Hull M, Landreth G, Lue L, Mrak R, Mackenzie IR, McGeer PL, O'Banion MK, Pachter J, Pasinetti G, Plata-Salaman C, Rogers J, Rydel R, Shen Y, Streit W, Strohmeyer R, Tooyoma I, et al.: Inflammation and Alzheimer's disease. Neurobiol Aging 2000 , 21:383-42I. 
68. Marchalant $Y$, Rosi S, Wenk GL: Anti-inflammatory property of the cannabinoid agonist WIN-552 I 2-2 in a rodent model of chronic brain inflammation. Neuroscience 2007, I 44: I 1 16-1522.

69. Rosi S, Pert CB, Ruff MR, McGann-Gramling K, Wenk GL: Chemokine receptor 5 antagonist D-Ala-peptide T-amide reduces microglia and astrocyte activation within the hippocampus in a neuroinflammatory rat model of Alzheimer's disease. Neuroscience 2005, 134:671-676.

70. Gasparini L, Ongini E, Wenk G: Non-steroidal anti-inflammatory drugs (NSAIDs) in Alzheimer's disease: old and new mechanisms of action. J Neurochem 2004, 91:521-536.

7I. McGeer PL, Rogers J: Anti-inflammatory agents as a therapeutic approach to Alzheimer's disease. Neurology 1992, 42:447-449.

72. Lau FC, Shukitt-Hale B, Joseph JA: Nutritional intervention in brain aging: reducing the effects of inflammation and oxidative stress. Subcell Biochem 2007, 42:299-318.

73. McGeer PL, McGeer EG: NSAIDs and Alzheimer disease: epidemiological, animal model and clinical studies. Neurobiol Aging 2007, 28:639-647.

74. Hayden KM, Zandi PP, Khachaturian AS, Szekely CA, Fotuhi M, Norton MC, Tschanz JT, Pieper CF, Corcoran C, Lyketsos CG, Breitner JC, Welsh-Bohmer KA, Cache County Investigators: Does NSAID use modify cognitive trajectories in the elderly? The Cache County study. Neurology 2007, 69:275-282.

75. Rogers J, Kirby LC, Hempelman SR, Berry DL, McGeer PL, Kaszniak AW, Zalinski J, Cofield M, Mansukhani L, Willson P, et al.: Clinical trial of indomethacin in Alzheimer's disease. Neurology 1993 43:1609-1611.

76. Yang S, Yang J, Yang Z, Chen P, Fraser A, Zhang W, Pang H, Gao X, Wilson $B$, Hong JS, Block ML: Pituitary adenylate cyclase-activating polypeptide (PACAP) 38 and PACAP4-6 are neuroprotective through inhibition of NADPH oxidase: potent regulators of microglia-mediated oxidative stress. J Pharmacol Exp Ther 2006, 319:595-603.

77. Qin L, Block ML, Liu Y, Bienstock RJ, Pei Z, Zhang W, Wu X, Wilson $B$, Burka T, Hong JS: Microglial NADPH oxidase is a novel target for femtomolar neuroprotection against oxidative stress. Faseb J 2005, 19:550-557.

78. Qin L, Liu Y, Qian X, Hong JS, Block ML: Microglial NADPH oxidase mediates leucine enkephalin dopaminergic neuroprotection. Ann N Y Acad Sci 2005, I 053: 107-120.

79. Choi SH, Lee DY, Chung ES, Hong YB, Kim SU, Jin BK: Inhibition of thrombin-induced microglial activation and NADPH oxidase by minocycline protects dopaminergic neurons in the substantia nigra in vivo. J Neurochem 2005, 95: 1755- 1765.

80. Cordle A, Landreth G: 3-Hydroxy-3-methylglutaryl-coenzyme A reductase inhibitors attenuate beta-amyloid-induced microglial inflammatory responses. I Neurosci 2005, 25:299-307.

8I. Qian L, Xu Z, Zhang W, Wilson B, Hong JS, Flood PM: Sinomenine, a natural dextrorotatory morphinan analog, is anti-inflammatory and neuroprotective through inhibition of microglial NADPH oxidase. J Neuroinflammation 2007, 4:23.

82. Zhang W, Hong JS, Kim HC, Zhang W, Block ML: Morphinan neuroprotection: new insight into the therapy of neurodegeneration. Crit Rev Neurobiol 2004, 16:27I-302.

83. Li G, Cui G, Tzeng NS, Wei SJ, Wang T, Block ML, Hong JS: Femtomolar concentrations of dextromethorphan protect mesencephalic dopaminergic neurons from inflammatory damage. Faseb J 2005, 19:489-496.

84. Liu Y, Qin L, Li G, Zhang W, An L, Liu B, Hong JS: Dextromethorphan protects dopamanergic neurons against inflammationmediated degeneration through inhibition of microglial activation. J Pharmacol Exp Ther 2003, 305: I-7.

85. Siu A, Drachtman R: Dextromethorphan: a review of $\mathbf{N}$-methyld-aspartate receptor antagonist in the management of pain. CNS Drug Rev 2007, 13:96-106.

86. Britton P, Lu XC, Laskosky MS, Tortella FC: Dextromethorphan protects against cerebral injury following transient, but not permanent, focal ischemia in rats. Life Sci 1997, 60:1729-1740.

87. Li G, Liu Y, Tzeng NS, Cui G, Block ML, Wilson B, Qin L, Wang T, Liu B, Liu J, Hong JS: Protective effect of dextromethorphan against endotoxic shock in mice. Biochem Pharmacol 2005, 69:233-240
88. Thomas DM, Kuhn DM: MK-80I and dextromethorphan block microglial activation and protect against methamphetamine-induced neurotoxicity. Brain Res 2005, 1050:190-198.

89. Liu Y, Qin L, Li G, Zhang W, An L, Liu B, Hong JS: Dextromethorphan protects dopaminergic neurons against inflammationmediated degeneration through inhibition of microglial activation. J Pharmacol Exp Ther 2003, 305:2/2-2/8.

90. Zhang W, Wang T, Qin L, Gao HM, Wilson B, Ali SF, Zhang W, Hong JS, Liu B: Neuroprotective effect of dextromethorphan in the MPTP Parkinson's disease model: role of NADPH oxidase. Faseb J 2004, 18:589-591.

91. Rosi S, Vazdarjanova A, Ramirez-Amaya V, Worley PF, Barnes CA Wenk GL: Memantine protects against LPS-induced neuroinflammation, restores behaviorally-induced gene expression and spatial learning in the rat. Neuroscience 2006, 142:1303-1315.
Publish with BioMed Central and every scientist can read your work free of charge

"BioMed Central will be the most significant development for disseminating the results of biomedical research in our lifetime. "

Sir Paul Nurse, Cancer Research UK

Your research papers will be:

- available free of charge to the entire biomedical community

- peer reviewed and published immediately upon acceptance

- cited in PubMed and archived on PubMed Central

- yours - you keep the copyright 